\title{
MicroRNA-200b inhibits the proliferation of hepatocellular carcinoma by targeting DNA methyltransferase 3a
}

\author{
XING-YU LI, XING-ZI FENG, JIAN-ZHONG TANG, KUN DONG, JUN-FENG WANG, \\ CHUN-CHENG MENG, JUN WANG, YI-WO MO and ZHI-WEI SUN \\ Department of Hepatobiliary Surgery, The First People's Hospital of Yunnan Province, \\ Kunming, Yunnan 650032, P.R. China
}

Received April 7, 2015; Accepted December 21, 2015

DOI: $10.3892 / \mathrm{mmr} .2016 .4995$

\begin{abstract}
Aberrant microRNA (miRNA or miR) expression has been reported to contribute to the pathogenesis of hepatocellular carcinoma (HCC). However, the involvement of specific miRNAs in HCC remains to be elucidated. The present study aimed to investigate the potential role of miR-200b and the mechanism underlying its function in hepatocarcinogenesis. The results of the present study demonstrated that the expression levels of miR-200b were significantly reduced in HCC tissue samples, as compared with normal liver (NL) and para-tumorous (PT) tissue samples. The results also revealed that miR-200b expression levels in HepG2 cells were significantly decreased compared with those in L02 cells. In addition, western blotting and reverse transcription-quantitative polymerase chain reaction demonstrated that the expression levels of DNA methyltransferase 3a (DNMT3a), a possible target gene for miR-200b, were significantly higher in HCC tissue samples, as compared with those in NL and PT tissue samples. Furthermore, the data suggested that DNMT3a was a direct target gene of miR-200b. Upregulated miR-200b expression in HepG2 cells led to a decrease in DNMT3a expression levels, and an inhibition of cell proliferation. These results suggested that miR-200b has an important role in hepatocarcinogenesis and acts by downregulating DNMT3a expression. Thus, miR-200b may be a promising target for HCC treatment.
\end{abstract}

\section{Introduction}

Hepatocellular carcinoma (HCC) is a leading cause of cancer-associated mortality, and is one of the most common malignant tumors with poor prognosis worldwide $(1,2)$. In clinical settings only a limited number of patients with $\mathrm{HCC}$

Correspondence to: Mr. Zhi-Wei Sun, Department of Hepatobiliary Surgery, The First People's Hospital of Yunnan Province, 157 Jinbi Road, Kunming, Yunnan 650032, P.R. China E-mail: sunzhiwei616@163.com

Key words: microRNA-200b, hepatocellular carcinoma, DNA methyltransferase $3 \mathrm{a}$, proliferation, apoptosis are eligible for potentially curative treatment options such as surgical resection followed by orthotopic liver transplantation $(3,4)$. Therefore, the development of effective therapeutic strategies for the treatment of greater numbers of patients with $\mathrm{HCC}$ is imperative. However, the pathogenesis of HCC remains unclear. $\mathrm{HCC}$ has long been considered the result of various genetic alterations that ultimately led to malignant transformation $(5,6)$. Cancer development is no longer thought to be induced by genetic and genomic alterations alone, but is also considered to be the result of epigenetic alterations $(7,8)$.

MicroRNAs (miRNAs or miRs) are a type of highly conserved non-coding small RNA that post-transcriptionally regulate the expression of their target genes (9). miRNAs have been demonstrated to regulate numerous aspects of cell activity, including metabolism, differentiation and development, proliferation, apoptosis and viral infection (10-15). Previous findings demonstrated that miRNAs have important roles in numerous types of malignant tumors, including HCC (16). In addition, numerous studies have demonstrated the existence of prognostic miRNAs in clinical tissue specimens of primary HCC, and miRNAs have been shown to have important regulatory roles in hepatocarcinogenesis (17-20).

The present study aimed to investigate the expression levels of miRNA-200b as well as those of its potential target DNA methyltransferase 3a (DNMT3a) in HCC.

\section{Materials and methods}

Patients and cell lines. Histologically normal liver (NL) tissue samples were obtained from 10 patients with gallbladder stones during a biopsy procedure. HCC and adjacent non-malignant para-tumorous (PT) tissue specimens were obtained from 44 hepatitis B-positive patients by radical hepatectomy. The patients, 33 males and 11 females, had undergone treatment at The First People's Hospital of Yunnan Province (mean age, $53.7 \pm 11.6$ years). HCC was confirmed in the tissue samples by pathological examination and were obtained with written informed consent from the patients. The present study was approved by the Institutional Review Board of the Fourth Military Medical University (Xian, China). The HepG2 and L02 cell lines were obtained from the Chinese Academy of Sciences (Shanghai, China) and cultured at $37^{\circ} \mathrm{C}$ with $5 \% \mathrm{CO}_{2}$ in RMPI-1640 medium (Sigma-Aldrich, St. Louis, MO, USA) 
supplemented with $10 \%$ fetal bovine serum (FBS; Invitrogen; Thermo Fisher Scientific, Inc., Waltham, MA, USA) until cell density reached $\sim 70-80 \%$.

MicroRNA arrays. MicroRNA arrays were conducted as previously described (21) on miR-200b from ten NL tissue samples, and $44 \mathrm{HCC}$ and corresponding non-malignant PT tissue samples. Briefly, 100 ng RNA was extracted from each tissue sample using TRIzol ${ }^{\circledR}$ (Invitrogen; Thermo Fisher Scientific, Inc.) and an RNeasy Mini kit (Invitrogen; Thermo Fisher Scientific, Inc.) according to the manufacturer's protocol. The tissue samples were subsequently hybridized by labeling with the miRCURY Hy3/Hy5 Power labeling kit (Exiqon A/S, Vedbæk, Denmark) and hybridizing on the miRCURY LNA ${ }^{\mathrm{TM}}$ Array (v.11.0). They were then scanned using an Axon GenePix 4000B microarray scanner (Thermo Fisher Scientific, Inc.).

Reverse transcription-quantitative polymerase chain reaction (RT-qPCR). Total RNA was extracted from the manually homogenized tissue samples as well as the cell lines using TRIzol ${ }^{\circledR}$ reagent, according to the manufacturer's protocol. Reverse transcription of $5 \mathrm{ng}$ RNA to cDNA was performed using a QuantiMir RT kit (System Biosciences, Mountain View, CA, USA). The following primers (Shanghai GenePharma Co., Ltd., Shanghai, China) were used: miR-200b forward, 5'-TCATCATTACCAGGCAGTATTA-3', and reverse, 5'-TCC ATCATTACCCGGCAGTATTA-3'; U6 forward, 5'-CTCGCT TCGGCAGCACA-3', and reverse, 5'-AACGCTTCACGA ATTTGCGT-3'; DNMT3a forward, 5'-CAATGACCTCTC CATCGTCAAC-3', and reverse, 5'-CATGCAGGAGGCGGT AGAA-3'; and $\beta$-actin forward, 5'-GAACGGTGAAGGTGA CAG-3', and reverse, 5'-TAGAGAGAAGTGGGGTGG-3'. miR-200b was amplified in a MyCycler thermal cycler (Bio-Rad Laboratories, Inc., Hercules, CA, USA) as follows: Denaturation at $95^{\circ} \mathrm{C}$ for $10 \mathrm{~min}$, and then 40 cycles of $95^{\circ} \mathrm{C}$ for $10 \mathrm{sec}, 60^{\circ} \mathrm{C}$ for $20 \mathrm{sec}$, and $72^{\circ} \mathrm{C}$ for $10 \mathrm{sec}$. DNMT3a was amplified as follows: Denaturation at $95^{\circ} \mathrm{C}$ for $10 \mathrm{~min}$, and then 40 cycles of $95^{\circ} \mathrm{C}$ for $15 \mathrm{sec}$ and $60^{\circ} \mathrm{C}$ for $1 \mathrm{~min}$. U6 RNA was used as an miRNA internal control, and $\beta$-actin was used to normalize the expression levels of total:mRNA in each sample. Values were calculated as ratios normalized to U6 or $\beta$-actin. The expression level of miRNA was defined based on the quantification cycle $(\mathrm{Cq})$, and relative expression levels were calculated using the $2^{-\Delta \Delta \mathrm{Cq}}$ method (22).

Transfection of miR-200b mimics. Synthesized Dharmacon miR-200b mimics were purchased from GE Healthcare Life Sciences (Pittsburgh, PA, USA). HepG2 cells $\left(2 \times 10^{6}\right)$ were cultured in RPMI-1640 medium supplemented with 10\% FBS at $37^{\circ} \mathrm{C}$ in $5 \% \mathrm{CO}_{2}$. When the HepG2 cells reached $30-50 \%$ confluence, they were transfected with miR-200b mimics $(60 \mathrm{nM})$ or miRNA mimic control using Lipofectamine ${ }^{\circledR} 2000$ (Invitrogen; Thermo Fisher Scientific, Inc.) according to the manufacturer's protocol. The cells were then harvested and protein expression levels were measured by western blotting $72 \mathrm{~h}$ post-transfection.

Western blot analysis. Western blotting was performed as previously described (23). Briefly, total protein was extracted using radioimmunoprecipitation buffer (Sigma-Aldrich) and $10 \mu \mathrm{g}$ of each sample was separated by SDS-PAGE (Bio-Rad Laboratories, Inc.) and transferred to polyvinylidene fluoride membranes (EMD Millipore, Billerica, MA, USA). The membranes were blocked with $5 \%$ skimmed milk in Tris-buffered saline with $0.1 \%$ (v/v)Tween 20 (TBST; EMD Millipore) and then incubated with primary antibodies with gentle agitation for $12 \mathrm{~h}$ at $4^{\circ} \mathrm{C}$. The membranes were then washed three times with TBST and incubated with goat anti-rabbit and goat anti-mouse peroxidase-conjugated secondary antibody (dilution, 1:3,000; Beyotime Institute of Biotechnology, Haimen, China; cat nos. A0208 and A0216). Rabbit anti-human monoclonal anti-DNMT3a (dilution, 1:1,000; Cell Signaling Technology, Inc., Danvers, MA, USA; cat. no. 3598) and mouse anti-human anti-GAPDH antibodies (dilution, 1:1,000; ProMab Biotechnologies, Inc., Richmond, CA, USA; cat. no. 20035) were used. Protein bands were visualized by chemiluminescence detection (EMD Millipore) and the quantification of band density was conducted using Image $\mathbf{J}$ (version 1.5; National Institutes of Health, Bethesda, MD, USA). GAPDH was used as an internal control, and all values were calculated as ratios normalized to GAPDH.

Identification of targets of miR-200b. TargetScan (www. targetscan.org) was used to identify potential targets of miR-200b. An important enzyme in DNA methylation, DNMT3a, was identified as one of the potential targets.

Luciferase activity assay. The 3'-untranslated region (UTR) of DNMT3a was amplified by PCR and inserted into a pGL3 vector (Promega Corporation, Madison, WI, USA). The PCR was conducted on a MyCycler thermal cycler under the following conditions: $50^{\circ} \mathrm{C}$ for $30 \mathrm{~min}$; $95^{\circ} \mathrm{C}$ for $95 \mathrm{~min}$; and 40 cycles of $95^{\circ} \mathrm{C}$ for $30 \mathrm{sec}$ and $55^{\circ} \mathrm{C}$ for $30 \mathrm{sec}$. A pGL3 construct containing DNMT3a 3'-UTR with point mutations in the seed sequence was synthesized using 30 reactions of the Quik-Change Lightning Site-Directed Mutagenesis kit (Agilent Technologies, Inc., Santa Clara, CA, USA) according to the manufacturer's protocol. The primers used for DNMT3a were as follows: Forward, 5'-GCTCTAGACGAAAAGGGT TGGACATCAT-3', and reverse, 5'-GCTCTAGAGCCGAGG GAGTCTCCTTTTA-3'.

HepG2 cells $\left(2 \times 10^{5}\right)$ were transfected using Lipofectamine ${ }^{\circledR}$ 2000 with the appropriate plasmids in 24 -well plates. The cells were then harvested and lysed with reporter gene cell lysis buffer (Beyotime Institute of Biotechnology) in order to conduct a luciferase activity assay $48 \mathrm{~h}$ post-transfection using a dual luciferase reporter assay system (Promega Corporation). Relative luciferase activity levels were normalized to Renilla luciferase activity, which served as an internal control.

MTT assay. An MTT assay was used to determine the effects of ectopic miR-200b mimics on HepG 2 cell proliferation. Briefly, HepG2 cells were transfected with miR-200b mimics using Lipofectamine ${ }^{\circledR} 2000$ and then seeded into 96-well plates at $5 \times 10^{3}$ cells/well in $200 \mu \mathrm{l}$ RPMI-1640 medium for $72 \mathrm{~h}$. MTT solution $[0.5 \mathrm{mg} / \mathrm{ml}$ in $20 \mu \mathrm{l}$ phosphate-buffered saline (PBS); Sigma-Aldrich] was added to each well and incubated for $4 \mathrm{~h}$ at $37^{\circ} \mathrm{C}$. An enzyme-labeled instrument (Thermo Fisher Scientific, Inc.) was used to measure the absorbance of each 

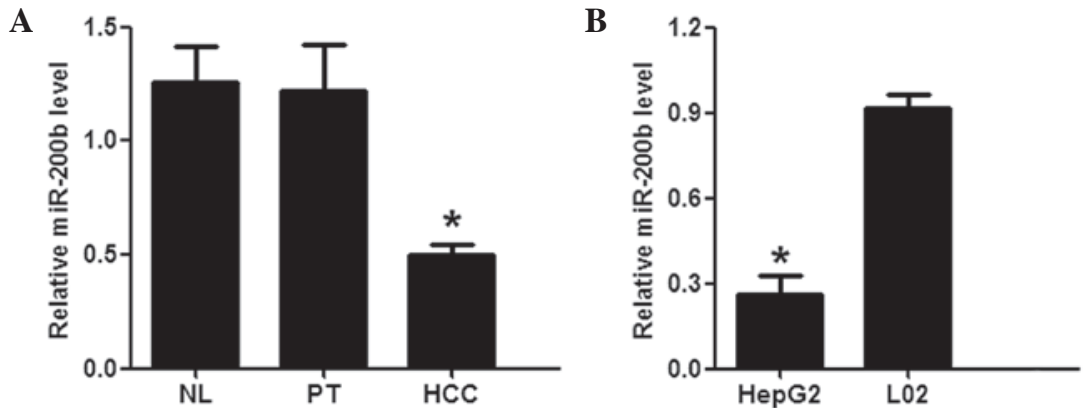

Figure 1. miR-200b expression levels are downregulated in HCC tissue samples and HepG2 hepatoma cell lines. (A) The expression levels of miR-200b in the NL, PT, and HCC tissue samples from 44 patients with hepatitis B-positive HCC, as determined by RT-qPCR. " $\mathrm{P}<0.05$, vs. the NL/PT groups. (B) The expression levels of miR-200b in the HepG2 and L02 cell lines, as determined by RT-qPCR. "P $<0.05$, vs. the L02 cells. The values are presented as means \pm standard error of the mean. All experiments were performed in triplicate, and similar results were obtained from each experiment. miR, microRNA; NL, normal liver; PT, para-tumorous; HCC, hepatocellular carcinoma; RT-qPCR, reverse transcription-quantitative polymerase chain reaction.

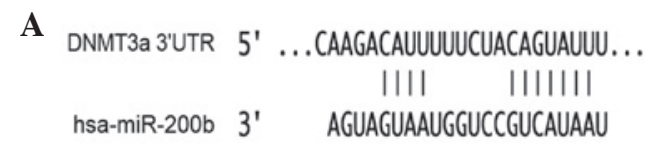

B

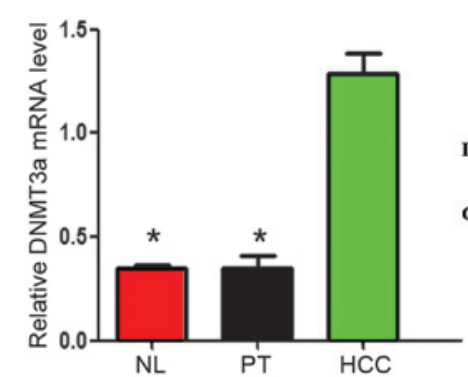

C

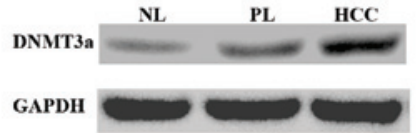

D

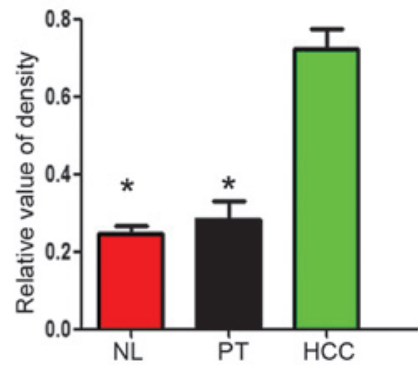

Figure 2. Expression levels of the miR-200b target gene DNMT3a are increased in HCC tissues samples compared with NL tissue samples. (A) Bioinformatics analysis suggested that DNMT3a was an important enzyme in DNA methylation, and a potential target of miR-200b. (B) The mRNA expression levels of DNMT3a in NL, PT, and HCC tissue samples were determined using reverse transcription-quantitative polymerase chain reaction. (C and D) Protein expression levels of DNMT3a in NL, PT and HCC tissue samples. The data are presented as means \pm standard error of the mean. All experiments were performed in triplicate and yielded similar results. ${ }^{*} \mathrm{P}<0.05$, vs. the HCC group. NL, normal liver; PT, para-tumorous; HCC, hepatocellular carcinoma; miR, microRNA; 3'-UTR; 3'-untranslated region; DNMT3a, DNA methyltransferase 3a.

well at $570 \mathrm{~nm}$. Data were obtained from three independent experiments.

TUNEL staining. DNA fragmentation of apoptotic cells was detected using a TUNEL kit (Sigma-Aldrich) according to the manufacturer's protocol. Briefly, $2 \times 10^{5}$ cells were cultured on cover slips for $48 \mathrm{~h}$ at $37^{\circ} \mathrm{C}$ with $5 \% \mathrm{CO}_{2}$. Following miR-200b mimic transfection for $72 \mathrm{~h}$, the cells were fixed in 4\% paraformaldehyde solution (EMD Millipore) in PBS for $30 \mathrm{~min}$ at room temperature. The cells were incubated with methanol solution containing $0.3 \% \mathrm{H}_{2} \mathrm{O}_{2}$ for $30 \mathrm{~min}$ at room temperature to block endogenous peroxidase activity, and then incubated in the TUNEL reaction mixture for $60 \mathrm{~min}$ at $37^{\circ} \mathrm{C}$ Nuclei were visualized with DAPI staining $(0.5-10 \mu \mathrm{g} / \mathrm{ml}$; Beyotime Institute of Biotechnology) for 10 mins. The cells were then visualized by fluorescence microscopy (DM4000B; Leica Microsystems GmbH, Wetzlar, Germany). Apoptotic cells were counted from four randomly selected fields in each sample.

Flow cytometry. Apoptotic cells were detected using double-staining with Annexin V-fluorescein isothiocyanate

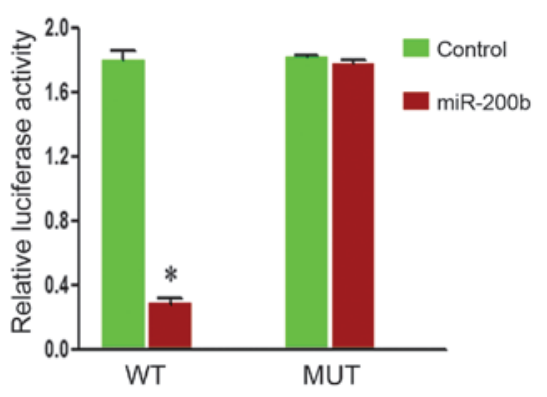

Figure 3. Ectopic miR-200b expression inhibits WT but not MUT DNMT3a 3'-UTR reporter activity in HepG2 cells. Cells were co-transfected with miR-200b and either a WT or MUT DNMT3a 3'-UTR reporter construct. A luciferase activity assay was performed $48 \mathrm{~h}$ following co-transfection. The data are presented as means \pm standard error of the mean. All experiments were performed in triplicate, and similar results were obtained from each experiment. "P $<0.05$, vs. the WT control group. miR, microRNA; WT, wild-type; MUT, mutant; 3'-UTR, 3'-untranslated region; DNMT3a, DNA methyltransferase $3 \mathrm{a}$.

(FITC)/propidium iodide (PI; Nanjing KeyGen Biotech Co., Ltd., Nanjing, China). Briefly, the cells were harvested $48 \mathrm{~h}$ post-transfection and stained with anti-Annexin $\mathrm{V}$ conjugated 
A
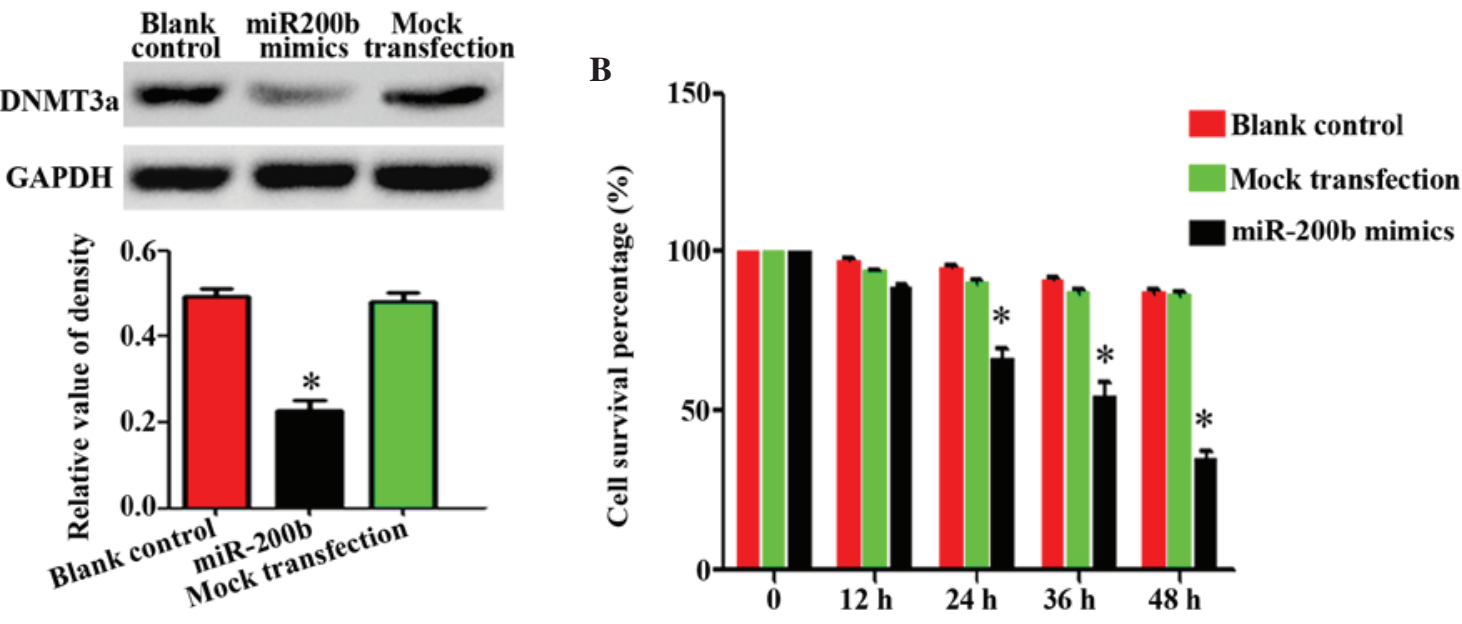

Figure 4. Ectopic miR-200b decreases DNMT3a expression levels and HepG2 cell proliferation. (A) miR-200b mimics were transfected into HepG2 cells, and the protein expression levels of DNMT3a were detected by western blotting. (B) At 0, 12, 24, 36, and $48 \mathrm{~h}$ post-miR-200b transfection, cell proliferation was measured by MTT assay. The data are presented as means \pm standard error of the mean. All experiments were performed in triplicate, and similar results were obtained for each experiment. " $\mathrm{P}<0.05$, vs. the blank control and mock transfection groups. miR, microRNA; DNMT3a, DNA methyltransferase $3 \mathrm{a}$.

A

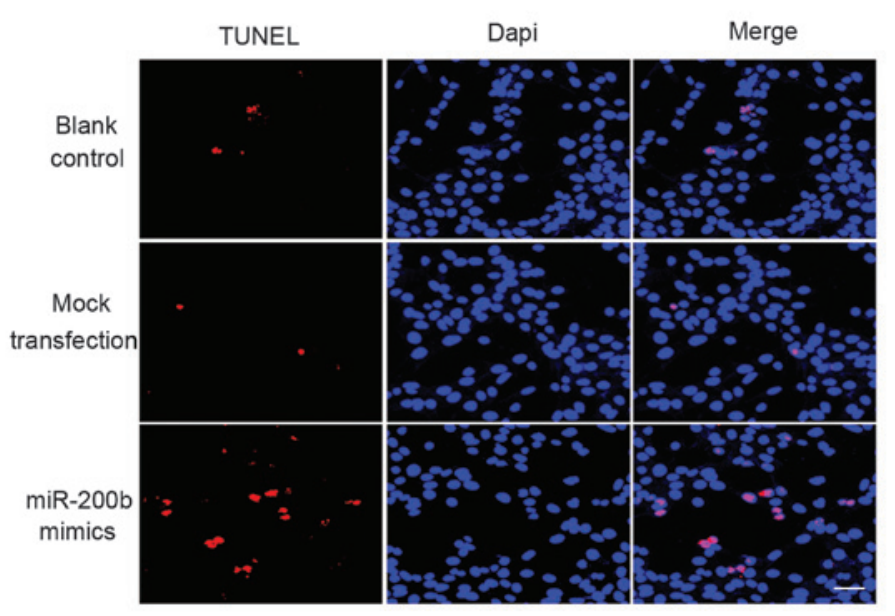

B
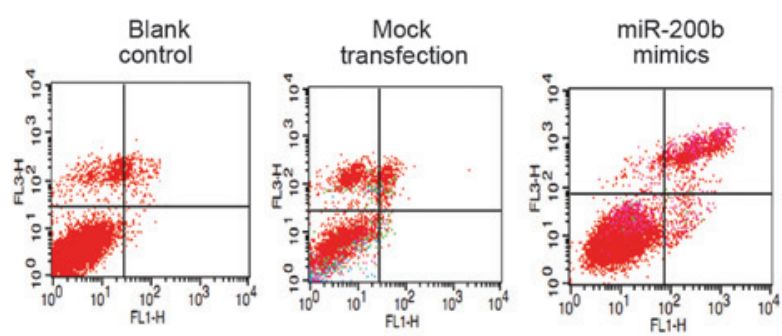

C

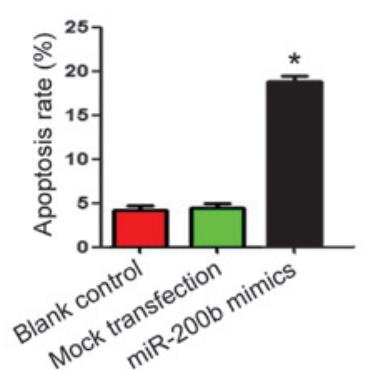

Figure 5. Ectopic miR-200b markedly increased apoptosis of HepG2 cells compared with the blank and negative controls. (A) miR-200b mimics were transfected into HepG2 cells, and apoptosis levels were determind $48 \mathrm{~h}$ post-transfection by TUNEL staining. Red, apoptotic cells; blue; DAPI. Magnification, x800. (B and C) The apoptosis levels were also determined by flow cytometry. The lower left quadrants represent live cells, the upper left represent early apoptotic cells, the lower right represent late apoptotic cells and the upper right quadrant represents dead cells. The data are presented as means \pm standard error of the mean. All experiments were performed in triplicate, and similar results were obtained for each experiment. "P<0.05, vs. the blank control/mock transfection groups. miR, microRNA; DAPI, 4',6-diamidino-2-phenylindole.

to FITC and PI for $15 \mathrm{~min}$ at room temperature. The cells were then detected using fluorescence-activated cell sorting FACS using a FACS Calibur obtained from BD Biosciences (Franklin Lakes, NJ, USA). The data were analyzed using CellQuest software (version 5.1; BD Biosciences).

Statistical analysis. All the experiments were repeated in triplicate, and the data were expressed as the mean \pm standard error of the mean. The results were analyzed using the Student's t-test and one-way analysis of variance. The statistical analyses were conducted using SPSS 19.0 software (IBM SPSS, Armonk, NY, USA) and $\mathrm{P}<0.05$ was considered to indicate a statistically significant result.

\section{Results}

miR-200b expression levels are downregulated in HCC tissue samples and HepG2 cell lines. To investigate miR-200b expression in HCC tissue samples, RT-qPCR was used to quantify miR-200b expression levels. miR-200b expression levels were significantly decreased in the HCC tissue samples, as compared with those in the NL and non-malignant PT tissue samples $(\mathrm{P}<0.05$; Fig. 1A). The expression levels of miR-200b were then evaluated in the HepG2 and L02 cells by RT-qPCR. The expression levels of miR-200b were significantly lower in the HepG2 cells, as compared to those in the L02 cells $(\mathrm{P}<0.05$; Fig. 1B). These results indicated that miR-200b 
expression levels are significantly decreased in HCC tissue samples and cell lines, suggesting that miR-200b is associated with hepatocellular carcinogenesis.

In silico prediction of DNMT3a as an miR-200b target. TargetScan was used to identify the potential targets of miR-200b. An important enzyme in DNA methylation, DNMT3a, was identified as one of the potential targets of miR-200b. The predicted binding site of miR-200b with the DNMT3a 3'-UTR is shown in Fig. 2A.

The expression levels of the potential miR-200b target gene DNMT3a are significantly increased in HCC tissue samples compared with NL tissue samples. The mRNA and protein expression levels of the miR-200b potential target gene DNMT3a were evaluated by RT-qPCR and western blot analysis. Compared with mRNA expression levels of DNMT3a in the NL $(0.318 \pm 0.047)$ or PT $(0.326 \pm 0.082)$ tissue samples, the mRNA expression levels of DNMT3a in the HCC $(1.295 \pm 0.093)$ tissue samples were significantly higher $(\mathrm{P}<0.05$; Fig. 2B). In addition, compared with the protein expression levels of DNMT3a in the NL $(0.214 \pm 0.037)$ and PT $(0.280 \pm 0.068)$ tissue samples, the protein expression levels of DNMT3a in the HCC $(0.722 \pm 0.014)$ tissue samples were also significantly higher $(\mathrm{P}<0.05$; Fig. $2 \mathrm{C}$ and $\mathrm{D})$.

DNMT3a is the direct target of miR-200b. To examine miR200b-DNMT3a interactions, DNMT3a complementary sites, with or without mutations, were cloned into the 3'-UTR of the firefly luciferase gene and co-transfected with miR-200b mimics or a negative control in HepG2 cells. The presence of miR-200b led to a significant reduction in the relative luciferase activity levels in the wild-type construct of the DNMT3a 3'-UTR in HepG2 cells $(\mathrm{P}<0.05)$. However, the mutant construct of the DNMT3a 3'-UTR reversed the suppressive effect of miR-200b in HepG2 cells (Fig. 3). These results suggest that DNMT3a is a direct target of miR-200b.

Ectopic miR-200b decreases the expression levels of DNMT3a and suppresses HepG2 cell proliferation. Western blotting was conducted to detect the protein expression levels of DNMT3a following miRNA-200b mimic transfection in HepG2 cells. DNMT3a protein expression levels were significantly decreased in the mimic group $(0.214 \pm 0.021)$, as compared with those in the blank control $(0.527 \pm 0.035)$ or mock transfection control group $(0.513 \pm 0.013$; $\mathrm{P}<0.05$; Fig. $4 \mathrm{~A}$ and $\mathrm{B})$.

To determine the role of miR-200b deregulation in hepatocarcinogenesis, an MTT assay, a TUNEL assay, and flow cytometry were used to determine the proliferation and apoptosis rates of HepG2 cells following miR-200b mimic exposure. The MTT assay demonstrated that at 24,36 and $48 \mathrm{~h}$ following miR-200b mimic exposure, the proliferation rate of HepG2 cells was reduced to 68,42 and $36.3 \%$ of the control, respectively (Fig. 4C). The differences between the miR-200b mimic-transfected and control groups at the above-mentioned time points were statistically significant $(\mathrm{P}<0.05)$, whereas the difference between the blank and negative control groups were not $(\mathrm{P}>0.05$; Fig. 4C). The apoptosis of HepG2 cells post-transfection with miR-200b mimics was evaluated by TUNEL assay and flow cytometry. Apoptosis levels were markedly increased in the miR-200b mimic group, as compared with the blank and negative control groups (Fig. 5).

\section{Discussion}

The present study aimed to investigate the possible role of miR-200b in hepatocarcinogenesis and to identify its target gene. The results demonstrated that, compared with NL and PT tissue samples, miR-200b expression levels were significantly reduced in HCC tissue samples. In addition, miR-200b expression levels in HepG2 cells were significantly decreased, as compared with those in L02 cells. Western blotting and RT-qPCR demonstrated that the expression levels of DNMT3a, a possible target gene for miR-200b, were significantly higher in HCC tissue samples, as compared with NL and PT tissue samples. Furthermore, the results of the present study demonstrated that DNMT3a was the direct target gene of miR-200b. Upregulated miR-200b expression in HepG2 cells led to a decrease in DNMT3a expression levels, and had an inhibitory effect on cell proliferation. These data suggested that miR-200b is an important factor in hepatocarcinogenesis, and acts by downregulating DNMT3a expression. miR-200b may therefore be a promising target for $\mathrm{HCC}$ treatment.

miRNAs are non-coding RNAs 19-25 nucleotides in length that have been demonstrated to regulate gene expression by inducing translational inhibition or cleavage of their target mRNAs through base pairing at partially or fully complementary sites (24-26). Numerous miRNAs have been demonstrated to function as tumor suppressor or oncogenes by regulating their target genes (27-29). Previous studies have demonstrated that various miRNAs are abnormally expressed in malignant HCC cells or tissue samples, as compared with normal hepatocytes or tissue samples (18,30-32). In the present study, the results revealed that miR-200b expression levels were significantly decreased in HCC tissue samples and in HepG2 cells, as compared with those in non-malignant liver tissue samples and LO2 cells.

Genomic stability is regulated by both genetic and epigenetic mechanisms (33). Promoter hypermethylation mediated by DNMTs is widely accepted as the predominant mechanism underlying the epigenetic inactivation of tumor suppressor genes (TSGs) (34,35). Previous studies have demonstrated that viral genes have important roles in regulating DNA methylation (36-38). However, the epigenetic mechanisms underlying virus-associated cancers are poorly understood. Numerous studies have suggested that hypermethylation is responsible for the silencing of TSGs in hepatocarcinogenesis (39-42). In addition, data from previous studies support a role for miRNAs as targets and effectors in aberrant mechanisms underlying DNA hypermethylation (43-45). The present study demonstrated that there exists an interaction between miR-200b and DNMT3a. Firstly, in silico analysis suggests that DNMT3a, an important enzyme in DNA methylation, may be one of the possible targets of miR-200b. Secondly, the results demonstrate that the mRNA and protein expression levels of DNMT3a are inversely correlated with miR-200b expression in HCC. Ectopic miR-200b expression led to a reduction in the expression levels of DNMT3a. Furthermore, DNMT3a was shown to be a direct target of miR-200b, as demonstrated by a luciferase activity assay. The results of the present study also demonstrate 
that ectopic miR-200b expression significantly suppressed the proliferation of HepG2 cells and induced apoptosis. These data suggest that miR-200b regulates DNMT3a expression and has a tumor suppressive role in HCC development.

Since the number of samples used in the present study was relatively small, further investigation with a larger number of samples is required. Furthermore, the regulatory mechanism underlying miR-200b expression downregulation in $\mathrm{HCC}$ requires investigation. In conclusion, the results of the present study suggest that miR-200b is an important factor in hepatocarcinogenesis, and acts by downregulating DNMT3a expression. Thus, miR-200b is a promising target for HCC treatment.

\section{Acknowledgements}

The authors of the present study are grateful to Dr Wang from the Department of Pharmacology and Neurology of Harvard Medical School (Boston, MA, USA) for the critical reading and modification of the manuscript.

\section{References}

1. El-Serag HB and Rudolph KL: Hepatocellular carcinoma: Epidemiology and molecular carcinogenesis. Gastroenterology 132: 2557-2576, 2007.

2. Thomas MB and Zhu AX: Hepatocellular carcinoma: The need for progress. J Clin Oncol 23: 2892-2899, 2005.

3. Llovet JM: Updated treatment approach to hepatocellular carcinoma. J Gastroenterol 40: 225-235, 2005.

4. Llovet JM and Bruix J: Novel advancements in the management of hepatocellular carcinoma in 2008. J Hepatol 48 Suppl 1: S20-S37, 2008

5. Farazi PA and DePinho RA: Hepatocellular carcinoma pathogenesis: From genes to environment. Nat Rev Cancer 6: 674-687, 2006.

6. Sanyal AJ, Yoon SK and Lencioni R: The etiology of hepatocellular carcinoma and consequences for treatment. Oncologist 15 Suppl 4: 14-22, 2010.

7. Franco R, Schoneveld O, Georgakilas AG and Panayiotidis MI: Oxidative stress, DNA methylation and carcinogenesis. Cancer Lett 266: 6-11, 2008.

8. Ziech D, Franco R, Pappa A and Panayiotidis MI: Reactive Oxygen Species (ROS)--Induced genetic and epigenetic alterations in human carcinogenesis. Mutat Res 711: 167-173, 2011.

9. Mattick JS and Makunin IV: Non-coding RNA. Hum Mol Genet 15: R17-R29, 2006.

10. Alvarez-Garcia I and Miska EA: MicroRNA functions in animal development and human disease. Development 132: 4653-4662, 2005.

11. Yao Y, Suo A-L, Li ZF, Liu LY, Tian T, Ni L, Zhang WG, Nan KJ, Song TS and Huang C: MicroRNA profiling of human gastric cancer. Mol Med Rep 2: 963-970, 2009.

12. Chan SY, Zhang YY, Hemann C, Mahoney CE, Zweier JL and Loscalzo J: MicroRNA-210 controls mitochondrial metabolism during hypoxia by repressing the iron-sulfur cluster assembly proteins ISCU1/2. Cell metabolism 10: 273-284, 2009.

13. Chen JF, Mandel EM, Thomson JM, Wu Q, Callis TE, Hammond SM, Conlon FL and Wang DZ: The role of microRNA-1 and microRNA-133 in skeletal muscle proliferation and differentiation. Nat Genet 38: 228-233, 2006.

14. Wang B, Cai Z, Lu F, Li C, Zhu X, Su L, Gao G and Yang Q. Destabilization of survival factor MEF2D mRNA by neurotoxin in models of Parkinson's disease. J Neurochem 130: 720-728, 2014

15. Sullivan CS and Ganem D: MicroRNAs and viral infection. Mol Cell 20: 3-7, 2005.

16. Meng F, Henson R, Wehbe-Janek H, Ghoshal K, Jacob ST and Patel T: MicroRNA-21 regulates expression of the PTEN tumor suppressor gene in human hepatocellular cancer. Gastroenterology 133: 647-658, 2007.

17. Su H, Yang JR, Xu T, Huang J, Xu L, Yuan Y and Zhuang SM: MicroRNA-101, down-regulated in hepatocellular carcinoma, promotes apoptosis and suppresses tumorigenicity. Cancer Res 69: 1135-1142, 2009.
18. Murakami Y, Yasuda T, Saigo K, Urashima T, Toyoda H, Okanoue $\mathrm{T}$ and Shimotohno K: Comprehensive analysis of microRNA expression patterns in hepatocellular carcinoma and non-tumorous tissues. Oncogene 25: 2537-2545, 2006.

19. Gramantieri L, Ferracin M, Fornari F, Veronese A, Sabbioni S, Liu CG, Calin GA, Giovannini C, Ferrazzi E, Grazi GL, et al: Cyclin G1 is a target of miR-122a, a microRNA frequently down-regulated in human hepatocellular carcinoma. Cancer Res 67: 6092-6099, 2007

20. Chen RX, Xia YH, Xue TC and Ye SL: Suppression of microRNA-96 expression inhibits the invasion of hepatocellular carcinoma cells. Mol Med Rep 5: 800-804, 2012.

21. Jiang J, Zhang Y, Yu C, Li Z, Pan Y and Sun C: MicroRNA-492 expression promotes the progression of hepatic cancer by targeting PTEN. Cancer Cell Int 14: 1-8, 2014.

22. Tang H, Deng M, Tang Y, Xie X, Guo J, Kong Y, Ye F, Su Q and Xie X: miR-200b and miR-200c as prognostic factors and mediators of gastric cancer cell progression. Clin Cancer Res 19: 5602-5612, 2013.

23. Feng D, Wang B, Ma Y, Shi W, Tao K, Zeng W, Cai Q, Zhang Z and Qin H: The Ras/Raf/Erk pathway mediates the subarachnoid hemorrhage-induced apoptosis of hippocampal neurons through phosphorylation of p53. Mol Neurobiol. 26 Oct, 2015 (Epub ahead of print)

24. Kim VN: MicroRNA biogenesis: Coordinated cropping and dicing. Nat Rev Mol Cell Biol 6: 376-385, 2005.

25. Carthew RW and Sontheimer EJ: Origins and mechanisms of miRNAs and siRNAs. Cell 136: 642-655, 2009.

26. Valencia-Sanchez MA, Liu J, Hannon GJ and Parker R: Control of translation and mRNA degradation by miRNAs and siRNAs. Genes Dev 20: 515-524, 2006.

27. Voorhoeve PM, le Sage C, Schrier M, Gillis AJ, Stoop H, Nagel R, Liu YP, van Duijse J, Drost J, Griekspoor A, et al: A genetic screen implicates miRNA-372 and miRNA-373 as oncogenes in testicular germ cell tumors. Adv Exp Med Biol 604: 17-46, 2007.

28. Hammond SM: MicroRNAs as tumor suppressors. Nat Genet 39: 582-583, 2007.

29. Hanke M, Hoefig K, Merz H, Feller AC, Kausch I, Jocham D, Warnecke JM and Sczakiel G: A robust methodology to study urine microRNA as tumor marker: MicroRNA-126 and microRNA-182 are related to urinary bladder cancer. Urol Oncol 28: 655-661, 2010.

30. Xu J, Wu C, Che X, Wang L, Yu D, Zhang T, Huang L, Li H, Tan W, Wang $C$ and Lin D: Circulating microRNAs, miR-21, miR-122, and miR-223, in patients with hepatocellular carcinoma or chronic hepatitis. Mol Carcinog 50: 136-142, 2011.

31. Ladeiro Y, Couchy G, Balabaud C, Bioulac-Sage P, Pelletier L, Rebouissou S and Zucman-Rossi J: MicroRNA profiling in hepatocellular tumors is associated with clinical features and oncogene/tumor suppressor gene mutations. Hepatology 47: 1955-1963, 2008.

32. Karakatsanis A,Papaconstantinou I, Gazouli M,Lyberopoulou A, Polymeneas G and Voros D: Expression of microRNAs, miR-21, miR-31, miR-122, miR-145, miR-146a, miR-200c, miR-221, miR-222, and miR-223 in patients with hepatocellular carcinoma or intrahepatic cholangiocarcinoma and its prognostic significance. Mol Carcinog 52: 297-303, 2013.

33. Li E: Chromatin modification and epigenetic reprogramming in mammalian development. Nat Rev Genet 3: 662-673, 2002

34. Luczak MW and Jagodziński PP: The role of DNA methylation in cancer development. Folia Histochem Cytobiol 44: 143-154, 2006.

35. Rajendran G, Shanmuganandam K, Bendre A, Mujumdar D, Goel A and Shiras A: Epigenetic regulation of DNA methyltransferases: DNMT1 and DNMT3B in gliomas. J Neurooncol 104: 483-494, 2011.

36. Feng J, Zhou Y, Campbell SL, Le T, Li E, Sweatt JD, Silva AJ and Fan G: Dnmt1 and Dnmt3a maintain DNA methylation and regulate synaptic function in adult forebrain neurons. Nat Neurosci 13: 423-430, 2010.

37. Viré E, Brenner C, Deplus R, Blanchon L, Fraga M, Didelot C, Morey L, Van Eynde A, Bernard D, Vanderwinden JM, et al: The Polycomb group protein EZH2 directly controls DNA methylation. Nature 439: 871-874, 2006.

38. Kuramochi-Miyagawa S, Watanabe T, Gotoh K, Totoki Y, Toyoda A, Ikawa M, Asada N, Kojima K, Yamaguchi Y, Ijiri TW et al: DNA methylation of retrotransposon genes is regulated by Piwi family members MILI and MIWI2 in murine fetal testes. Gene Dev 22: 908-917, 2008 
39. Xie Y,Liu J, Benbrahim-Tallaa L, Ward JM, Logsdon D, Diwan BA and Waalkes MP: Aberrant DNA methylation and gene expression in livers of newborn mice transplacentally exposed to a hepatocarcinogenic dose of inorganic arsenic. Toxicology 236: 7-15, 2007.

40. Pogribny IP, Ross SA, Wise C, Pogribna M, Jones EA, Tryndyak VP, James SJ, Dragan YP and Poirier LA: Irreversible global DNA hypomethylation as a key step in hepatocarcinogenesis induced by dietary methyl deficiency. Mutat Res 593: 80-87, 2006.

41. Zhu R, Li BZ, Li H, Ling YQ, Hu XQ, Zhai WR and Zhu HG: Association of p16INK4A hypermethylation with hepatitis B virus $\mathrm{X}$ protein expression in the early stage of $\mathrm{HBV}$-associated hepatocarcinogenesis. Pathol Int 57: 328-336, 2007.

42. Park IY, Sohn BH, Yu E, Suh DJ, Chung YH, Lee JH, Surzycki SJ and Lee YI: Aberrant epigenetic modifications in hepatocarcinogenesis induced by hepatitis B virus $\mathrm{X}$ protein. Gastroenterology 132: 1476-1494, 2007.
43. Fabbri M, Garzon R, Cimmino A, Liu Z, Zanesi N, Callegari E, Liu S, Alder H, Costinean S, Fernandez-Cymering C, et al: MicroRNA-29 family reverts aberrant methylation in lung cancer by targeting DNA methyltransferases $3 \mathrm{~A}$ and 3B. Proc Natl Acad Sci USA 104: 15805-15810, 2007.

44. Garzon R, Liu S, Fabbri M, Liu Z, Heaphy CE, Callegari E, Schwind S, Pang J, Yu J, Muthusamy N, et al: MicroRNA-29b induces global DNA hypomethylation and tumor suppressor gene reexpression in acute myeloid leukemia by targeting directly DNMT3A and 3B and indirectly DNMT1. Blood 113: 6411-6418, 2009.

45. Pan W, Zhu S, Yuan M, Cui H, Wang L, Luo X, Li J, Zhou H, Tang Y and Shen N: MicroRNA-21 and microRNA-148a contribute to DNA hypomethylation in lupus CD4+ T cells by directly and indirectly targeting DNA methyltransferase 1 . J Immunol 184: 6773-6781, 2010. 